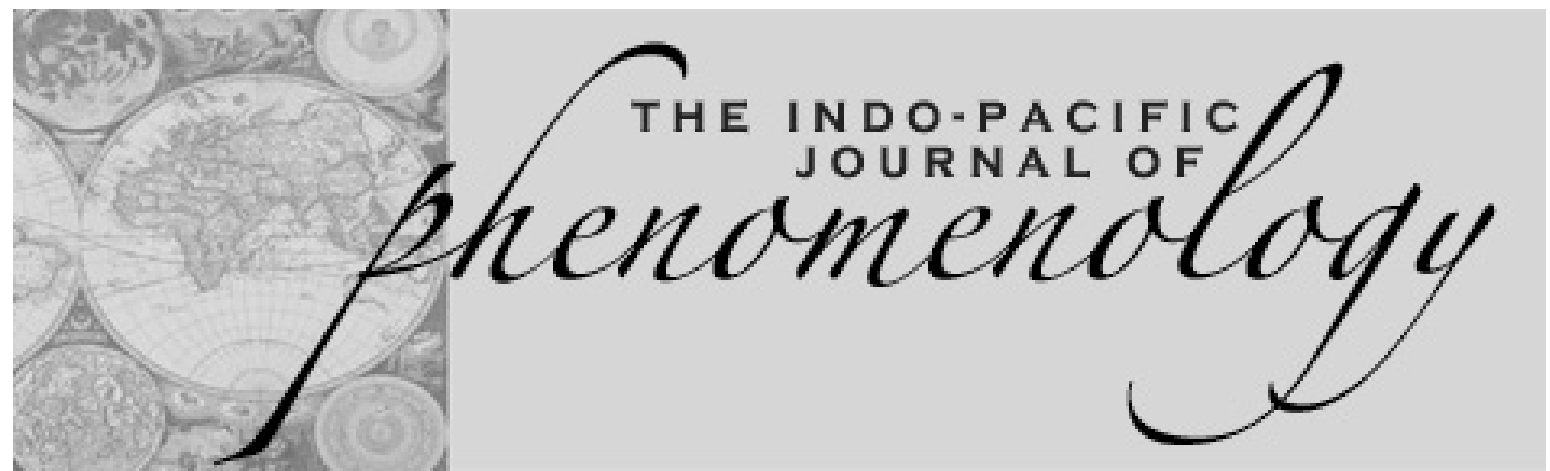

\title{
Adolescents, their Parents, and Information and Communication Technologies: \\ Exploring Adolescents' Perceptions on How these Technologies Present in Parent-Adolescent Relationships
}

\author{
by Willem Odendaal, Charles Malcolm, Shazly Savahl, and Rose September
}

\begin{abstract}
The differences between parents and adolescents in relation to information and communication technologies (ICT) are well documented, yet little is known about how adolescents experience these differences. The study reported in this paper therefore aimed to elucidate adolescents' views on these differences, and in the process to explore the possible impact on parent-adolescent relationships. The participants comprised 23 Grade 10 learners, conveniently selected from three high schools in the Cape Peninsula, South Africa. The learners participated in focus group discussions and reported on the following: their experiences and perceptions regarding their parents' level of techno-literacy; their attitude towards, and use of, ICT in comparison with that of their parents; and parental regulations imposed on their use of these technologies. Thematic content analysis was applied to delineate themes emerging from the texts. Although the study confirmed that differences between parents and adolescents exist in relation to ICT, it calls into question other research that too readily portrays this aspect as being negatively experienced by the adolescent, and a threat to healthy parent-adolescent relationships. It was also evident that it is not possible to be conclusive about the impact that ICT may have on parent-adolescent relationships, without information on how parents and adolescents relate above and beyond these technologies. The importance of ICT in adolescents' lives emphasises the need to unravel the impact it may have on their well-being.
\end{abstract}

\section{Introduction}

Across time, parent-adolescent relationships have been complicated by the developmental needs of adolescents, and parents' struggle to respond appropriately to these needs. Adolescents' quest for autonomy and their own identity, the importance of the peer group, or experimenting with sex (Berk, 2000; Gullotta, Adams \& Markstrom, 2000) in themselves carry, and have historically carried, the potential for a rift between parents and adolescents. Adding to this tension is the reality that each generation's actions and construction of meaning are guided by the specific cultural artefacts of its time (Gullotta et al., 2000). If this is applied to parents and adolescents in the $21^{\text {st }}$ century, it implies that parents, who did not grow up with information and communication technologies (ICT), as contemporary adolescents have, might be estranged from the ways in which adolescents use these technologies, for example in socialising with peers. There is ample evidence in the literature that illustrates how the differences between parents and adolescents regarding their attitudes towards, and use of, these

The IPJP is a joint project of Rhodes University in South Africa and Edith Cowan University in Australia. This document is subject to copyright and may not be reproduced in whole or in part via any medium (print, electronic or otherwise) without the express permission of the publishers. 
digital technologies may add to the complexity of their relationship.

The ease and enthusiasm with which the "Net generation" (Wright, 2001, p. 37), being today's techno-literate youth, engages with ICT may surpass their parents' enthusiasm and ability to adapt to this new environment (Berson \& Berson, 2003; Montgomery, 2000; Wright, 2001). Consequently, parents are reluctant to engage with their children around ICT (Casas, 1998; September \& Savahl, 2002), lessening communication and interaction between them. It is even argued that, when adolescents are the more confident users, parental authority is threatened (Aphek, 2003; Casas, Alsinet, Perez Tornero, Figuer, Conzalez, \& Pascual, 2001; Stahl \& Fritz, 2002). Since these technologies increase adolescents' sense of autonomy (Davie, Panting \& Charlton, 2004; Environics, 2001; Izenberg \& Lieberman, 1998; Kline \& Botterill, 2001; Prezza, Pacilli \& Dinelli, 2004), ICT may very well have become the vehicle to capture the turmoil in parentadolescent relationships.

There is also a divergence in opinion regarding the usefulness of ICT. Whilst parents emphasise the educational benefits of these technologies, for adolescents it is all about fun and games (Environics, 2001; Izenberg \& Lieberman, 1998; Kline \& Botterill, 2001; Nachmias, Mioduser \& Shemla, 2003; September \& Savahl, 2002; Shaw, 2002; Skinner, Biscope, Poland \& Goldberg, 2003; Suoranta, 2003; Wolak, Mitchell \& Finkelhor, 2003). Parents are concerned that the use of ICT may lead to social isolation and anti-social behaviours (Gross, Juvonen \& Gable, 2002), but the "Net generation" thrives on the new horizons opened up by digital technologies (Aphek, 2003; Biocca, 2000; Suoranta, 2003). Furthermore, parents may perceive cell phones as useful tools that give them a sense of protection over and access to their children, yet Davie and colleagues (2004) found that Hong Kong adolescents rank status/fashion and the socialising opportunities offered by cell phones as the most important benefits of cell phones.

Finally, parents have to come to terms with the fact that ICT facilitate adolescents' socialising needs in ways that may be very alien to them. Face-to-face communication has been supplemented with online communications. Moreover, cybersex and internet pornography is a reality amongst adolescents (Strasburger, 2004; Suler, 1998), and cellular telephones offer more socialising opportunities outside parental control than does the conventional landline (Prezza et al., 2004). Parental concerns around these issues (Berson \& Berson, 2003; Shaw,
2002) are in stark contrast with how adolescents embrace the many communication facilities offered by ICT (Biocca, 2000; Montgomery, 2000; Nachmias et al., 2003; Rideout, Foehr, Roberts \& Brodie, 1999).

There may be disagreement about the claim that today's digital technologies are isolating parents more deeply from adolescents than ever before (Leland, Gordon, Underwood, Weingarten \& Figuero, 1999), that parents are less able to act as socialising agents (Aphek, 2003; Casas et al., 2001; September \& Savahl, 2002), or that healthy parent-adolescent relationships are at greater peril of breakdown today (Aphek, 2003; Leland et al., 1999). What cannot be disputed is that ICT have become intrinsic to parentadolescent relationships, and the perceived need to explore how adolescents experience this is what motivated this study. Based on the literature, three research questions were developed:

- How do adolescents perceive their parents' level of techno-literacy?

- What are reported by adolescents as the differences between them and their parents regarding attitudes towards, and use of, ICT?

- What is the nature of adolescents' accounts of parents regulating their use of ICT?

\section{Methodology}

As the purpose of the current study was to conduct an in-depth analysis of adolescents' perceptions, a qualitative framework was adopted. The analysis draws on data collected via three groups conducted with 23 Grade 10 learners, between the ages of 14-16, attending middle-income state schools in the Cape Peninsula. While the participants were conveniently selected and no attempt was made at representivity, each of the focus groups consisted of between 7-8 participants and included males and females as well as learners from a range of cultural backgrounds. The groups were conducted by a facilitator, assisted by a co-facilitator/note taker. A semi-structured interview schedule was followed to ensure that all relevant items were covered whilst retaining the flexibility and exploratory nature of qualitative research. With the permission of the participants, a dictaphone was used to capture the responses verbatim. The study followed the ethical principles outlined by Alderson (1995) and was conducted with the permission of the Western Cape Education Department and the participating schools. Confidentiality and anonymity were assured, with group members participating voluntarily and with informed consent. The data was analysed by means of a process of thematic content analysis,

The IPJP is a joint project of Rhodes University in South Africa and Edith Cowan University in Australia. This document is subject to copyright and may not be reproduced in whole or in part via any medium (print, electronic or otherwise) without the express permission of the publishers. 
which aims to delineate recurring themes emerging after numerous readings of the texts (Patton, 2002).

\section{Discussion}

The results of the study are presented in terms of the following two thematic categories. Theme 1 deals with whether adolescents experience the differences between themselves and their parents in relation to ICT in a positive or negative way. Theme 2 covers issues that complicate parent-adolescent relationships as a result of adolescents' use of ICT.

\section{Theme 1: Optimism despite the differences}

Firstly, for the majority of participants, parents are perceived as knowing less than adolescents about digital technologies. This may be an accepted truism, but the way in which this was reported, revealed something about the possible impact it may have on the relationship. It was clear that for some it is annoying:

"Yeah, what's the use if you try to explain and he doesn't like get anything?" (Male participant), and even an embarrassment: "They are backwards. They do know nothing about this." (Female participant)

It can be deduced from this that, for these adolescents, their parents' lack of familiarity with modern technology, and hence ICT illiteracy, may have a negative impact on their relationship. This deduction is limited by the fact that the participants were not questioned on their interaction with their parents outside of ICT. It is possible that some of these participants are also irritated with their parents' 'walk and talk' in general. If so, the technologies in the home are only an extension of an already problematic relationship and not the catalyst.

The reverse response was from participants who seemed to be more patient towards their parents:

"I will not say my parents are really backwards, but it's like they don't see the point." (Female participant)

These participants acknowledged that their parents are not techno-literate, but offered reasons for this, of which the most salient was given in the following excerpt:

"They never grew up with that technology,

that's why they don't bother with that stuff." (Male participant)
In this regard, a female participant contextualised her parents' lack of skills in terms of an issue pertaining to the local context of the study:

"Like if your parents come from an
advantaged family then you have the
advantage of getting into technology and
be exposed to those new things ... if you
come from a disadvantaged family then
you wouldn't have those opportunities."

From the latter responses it is tempting to conclude that, in these families, technologies do not evoke negative emotions and strain relationships. However, such a conclusion would need to take cognisance of the fact that no information on the nature of the preexisting or encompassing relationship was obtained. When adolescents display patience and understanding towards their parents' lesser knowledge about ICT, it may be indicative of how they normally interact with their parents. Therefore the authors have to concede that, to make valid inferences about the impact of ICT, the context, in this case the pre-existing relationship between parent and adolescent, needs to be accounted for (see Gross et al., 2002; Wolak et al., 2003; Ybarra \& Mitchell, 2004).

Given this limitation, this study calls into question previous researchers' conclusions that ICT are undermining of parental authority in their relationship with their teens (Aphek, 2003; Casas, 1998; Casas et al., 2001). The researchers' interpretation of reasons offered for parents' ignorance around ICT is that these participants did not belittle or demean their parents, as might have been the case if they did not respect their parents. It may be true that children are adapting more easily to the phenomenon of digital technologies than parents (Montgomery, 2000; Wright, 2001), but it is not that easy to conclude that this impacts negatively on the relationship, or that adolescents are prone to rejecting their parents' authority over them because of their parents' perceived lack of techno-literacy.

What has been reported in the literature about parents' reluctance to engage with their children around these technologies (Casas, 1998; Environics, 2001; Savahl \& September, 2004) cannot be generalised. A number of participants indicated that, because of the lack of ICT skills, their parents ask them for help:
"My mother has a cell phone ... with a radio and a camera and I have to show her to get to the gallery, where the photos are and show her all the pictures and all that ...." (Female participant)

The IPJP is a joint project of Rhodes University in South Africa and Edith Cowan University in Australia. This document is subject to copyright and may not be reproduced in whole or in part via any medium (print, electronic or otherwise) without the express permission of the publishers. 
This participant portrayed this as something that made her feel good about herself, and thus the interaction is interpreted as positive.

Finally, across all three groups there was ample evidence to support the known fact that parents accentuate the educational benefits (Environics, 2001; September \& Savahl, 2002) and that adolescents celebrate the entertainment and excitement offered by ICT (Izenberg \& Lieberman, 1998; Kline \& Botterill, 2001; Nachmias et al., 2003; September \& Savahl, 2002; Shaw, 2002; Skinner et al., 2003; Suoranta, 2003; Wolak et al., 2003). This is how the participants responded when asked about their use of ICT:

\section{[What do you use the Internet for?] \\ "Surf the Net, play games, listen to music and all that stuff." (Male participant)}

\section{[Do you use Internet for school projects?] \\ "Sometimes but mostly for fun, because we don't really get that deep research projects." (Female participant)}

Parents, as reported by the participants, seldom use the computer and Internet for fun:

“... it's more like for work if they have to type something." (Male participant)

Apart from this difference, the enthusiasm with which children engage with ICT may surpass their parents' enthusiasm about these technologies (Montgomery, 2000; Wright, 2001). This is how some participants described their enthusiasm:

"I'm on the computer $24 / 7^{*} . "$ (Male
participant)
['Abbreviation for 24 hours, seven days a week.]
"Weekends you don't see me elsewhere
but only on the computer." (Male
participant)

Although no parents participated in the study, it would be fair to assume, in the light of the general indications of the study, that they would not describe themselves as " $24 / 7$ " users of ICT at home.

It cannot be disputed that ICT have become the prime cultural artefact of our times, and there are undoubtedly profound differences between parents and adolescents regarding these technologies. But the unexpected finding is that these generational differences may be far less detrimental to healthy parent-adolescent relationships than assumed. Digital technologies increase communication opportunities in the home; whether this is conducive or not to the relationship between parents and adolescents may not lie in the computer or the cell phone, but in their existing relationship outside ICT.

\section{Theme 2: Flagging issues for the relationship}

Based on responses from the participants on their use of ICT, there are issues that parents need to be cognisant of, as these may impact on how they interact with their adolescents with respect to ICT.

Acceptance by peers is, and will remain, a developmental imperative during adolescence (Berk, 2000), and the importance to adolescents of having and using ICT in their socialising activities should not be ignored by parents. One female participant illustrated this point by saying that

\section{"technology and social life goes together. If there's trouble with the one then it will affect the other side also."}

A greater responsibility rests with parents to come to terms with the fact that a cell phone is not perceived as just a communication tool (Davie et al., 2004), but

\section{"For young people like us it's more like a status to have a good brand." (Female participant)}

All generations of teenagers adopt status symbols that are greatly desired and for which they "... would like slit their wrists ..." (Male participant) if they do not acquire them. This comment was made in reference to adolescents' urge to own cell phones. In this era, such considerations inevitably extend to digital equipment. A typical parental response to adolescents demanding the peer-accepted model of cell phones or having the latest computer games, is captured in the following excerpt:

\section{They get frustrated when you tell them you must have that brand of cell phone, because they will tell you that they had to live without it when they were young ... they don't worry about the brand they buy." (Female participant)}

It can be expected that for those parents who are not enthusiastic about digital technologies, and who fail to understand the social significance of having a computer or access to the Internet at home, these demands may be seen as superfluous. As such it may impede on the relationship.

The IPJP is a joint project of Rhodes University in South Africa and Edith Cowan University in Australia. This document is subject to copyright and may not be reproduced in whole or in part via any medium (print, electronic or otherwise) without the express permission of the publishers. 
A finding of this study that resonates with what is reported in the literature is that parents are ignorant about the content of adolescents' ICT activities (Kline \& Botterill, 2001; Rideout et al., 1999; Roberts, 2000). The participants reported, as in the case of their international counterparts, that they are left on their own in their use of ICT. Comments such as "I got no boundaries" (Male participant) and "There are no rules" (Female participant) were echoed in all three groups. This may suit adolescents well, but given the darker side of digital technologies, such as exploitation in chat rooms (Suler, 1998), bullying on cell phones (Davie et al., 2004), excessive violence in gaming (Walton \& Jansen, 2003) or age-improper sex content (Strasburger, 2004), parents should be alerted to what adolescents are engaging with when using these technologies. We argued earlier that ICT can increase communication opportunities between parents and adolescents, but this should not be limited to asking for technical advice from the adolescent.

When participants were asked to compare parents' regulations in respect of ICT with those regarding their conventional face-to-face ways of socialising, meeting with friends and dating, the following revealing comment was made:

"... when it comes to my social life, she wants to prepare me to handle this right. The time she experienced childhood there was not technology and now we're experiencing it together .... But then with my social life she thinks that she knows everything." (Female participant)

From this it can be concluded that parents, due to their familiarity with the domain, feel confident to advise adolescents about choosing friends and how to behave when going out with friends, but not concerning the use of digital technologies. Being adolescents once, parents may be familiar with X-rated movies and magazines, but this is something different when adolescents are watching a male's indecent exposure through a web camera in a chat room visit (as was reported by a participant).

Two other reasons were offered as to why parents are more strict in regulating adolescents' face-to-face socialising:

“... because with our social life parents can still control it in a way, but with technology you can't really control because it's everywhere, and one parent can not stop such a thing." (Female participant)

"I think if parents had some kind of proof that technology can harm you in a way, then they would be more strict. But they know friends and all those other things can influence you in either a bad way or a good way." (Female participant)

What we are arguing is that, because of the different manifestations of long-standing adolescent issues in ICT, this may alienate parents from their adolescents. Parents' regulations around the digital technologies should not be centred on limit setting, which was found to be the case in this study (also see Kline \& Botterill, 2001; Suoranta, 2003). According to Walsh (2000), parents with a high level of media knowledge are more consistent in regulating their children's media activities, monitor these activities more closely, and introduce alternative activities to children. It is not suggested that parents become avid gamers or Internet surfers, but it may lessen the digital gap if they do have informed views of the different digital technologies and related activities that adolescents are engaging with.

Finally, there were participants that referred to the importance of the pre-existing relationship regarding parental regulations around adolescent use of ICT. The following excerpts give evidence of this:
"I think it [the use of ICT] depends on the trust between your family. If you come from a very close family then there's this bond between you ... I don't have really boundaries because I know what's right and wrong." (Female participant)
"Confidence allow: As long as I don't break their confidence then they allow me to use the computer as I want to." (Male participant)

Another participant reported regulating her own behaviours around what she allows herself to watch on television:

\section{"I got my limits. There are certain things I wouldn't watch, like the Saturday movies that all the guys want to watch." (Female participant)}

From this it can be concluded that parents' values and norms do come into play when adolescents engage with digital technologies. As such, adolescents' use of ICT becomes an affirmation of the relationship with

The IPJP is a joint project of Rhodes University in South Africa and Edith Cowan University in Australia. This document is subject to copyright and may not be reproduced in whole or in part via any medium (print, electronic or otherwise) without the express permission of the publishers. 
their parents outside the digital environment. Those who are discouraged by all the possible negatives that ICT can bring into parent-adolescent relationships should pay heed that there might also be another side to this perspective.

\section{Conclusion}

The findings in this study lead the authors to be more optimistic than expected about how adolescents experience differences between themselves and their parents regarding ICT.

Yes, parents may be the lesser skilled members in the household, and may not enthusiastically embrace the entertainment facilities of these technologies, but this need not uproot and distort healthy parent-adolescent relationships. Adolescents were more tolerant regarding this, and some referred to the relevance of the relationship outside the digital environment in adolescents' use of ICT. It seems as if the biggest challenge for today's parents is to realise that these technologies have become the medium that facilitates adolescents' developmental needs. In writing the instruction manual for the use of ICT, social scientists have an important role to play in equipping both parents and adolescents to optimise the benefits of these technologies. This should be done in the awareness that pre-existing factors may influence how the users construct the meaning of their activities.

\section{Limitations and Recommendations}

The limitations of this study - which include not contextualising the participants' responses within their relationship with their parents around other issues, and not including parents in the study - may serve as recommendations as to what should be included in future research. The study's failure to provide more satisfactory answers on how ICT are shaping interpersonal relationships, highlights the need for more qualitative studies in this field. We may have the numbers regarding ICT use, but we are still some way from understanding the psychological impact that these technologies may have on the user.

\begin{abstract}
About the Authors
Willem Odendaal is a registered Research Psychologist, and currently employed as a consultant at the Medical Research Council. Prior to his postgraduate studies in psychology (Honours at the University of South Africa and MA in Research Psychology at the University of the Western Cape), Willem was a high school teacher for thirteen years, which explains his keen interest in adolescent issues. His other research interests are in home visitation programmes in low-income contexts and programme evaluation. Willem is also an active member of the Psychological Society of South Africa (PsySSA).

Charles Malcolm is currently Professor of Clinical Psychology at the University of the Western Cape, and Head of the Psychology Department. He obtained an MPsych degree from the University of the Witwatersrand (Wits) and a $\mathrm{PhD}$ degree from Rhodes University. He also completed a doctoral clinical internship at Rochester University in New York. He has previously held adjunct teaching positions at Wits, the University of Cape Town, Rhodes and Stellenbosch universities. He has an interest in phenomenological approaches to psychotherapy and in the application of qualitative research methods to psychotherapy, psychological phenomena and to the health sciences in general.

Shazly Savahl holds a MA degree in Research Psychology from the University of the Western Cape. His research interests are in the areas of childhood, child well-being and social indicators. He is currently completing a PhD dissertation entitled Ideological Constructions of Childhood.

Professor Roseline September has a PhD in Social Work. She currently holds the position of Senior Lecturer at the University of the Western Cape. Her research interests are related to the protection and well-being of children. Over the past ten years she has worked closely with the Department of Social Development and has been involved in writing numerous government policy documents, as well as the drafting of legislation.
\end{abstract}

\title{
References
}

Alderson, P. (1995). Listening to children: Children, ethics and social research. London: Barnardos.

The IPJP is a joint project of Rhodes University in South Africa and Edith Cowan University in Australia. This document is subject to copyright and may not be reproduced in whole or in part via any medium (print, electronic or otherwise) without the express permission of the publishers. 
Aphek, E. (2003). Children of the information age: A reversal of roles. Retrieved April 14, 2004, from http://www.acm.org/ubiquity/views/eaphek-2html

Berk, L. E. (2000). Child development (5 $5^{\text {th }}$ ed.). Boston: Allyn \& Bacon.

Berson, I. R., \& Berson, M. J. (2003). Digital literacy for effective citizenship. Social Education, 67, 164-175.

Biocca, F. (2000). New media technology and youth: Trends in the evolution of new media. Journal of Adolescent Youth, 27, 22-29.

Casas, F. (1998). Videogames: Between parents and children. The Second International Conference on Children and Competence: Children, Technology and Culture. London: Brunel University.

Casas, F., Alsinet, C., Perez Toreno, J. M., Figuer, C., Conzales, M., \& Pascual, S. (2001). Information technologies and communications between parents and children. Psychology in Spain, 5, 33-46.

Davie, R., Panting, C., \& Charlton, T. (2004). Mobile phone ownership and usage among pre-adolescents. Telematics and Informatics, 21, 359-373.

Environics, (2001). Young Canadians in a wired world: The students'view. Report prepared by Environics Media Awareness Network. Retrieved June 12, 2004, from http://www.media-wareness.ca/english/specialinitiatives/surveys/students-survey.cfm

Gross, E. F., Juvonen, J., \& Gable, S. L. (2002). Internet use and well being in adolescence. Journal of Social Issues, $58,75-98$.

Gullotta, T. P., Adams, G. R., \& Markstrom, C. A. (2000). The adolescent experience (4 ${ }^{\text {th }}$ ed.). California: Academic Press.

Izenberg, N., \& Lieberman, D. A. (1998). The web, communication trends, and children's health: Part 4. How children use the web. Clinical Pediatrics, 37, 335-340.

Kline, S., \& Botterill, J. (2001). Media use audit for B.C. teens: Key findings. Report prepared for distribution to B.C. Schools, Media Analysis Laboratory, Simon Fraser University. British Columbia. Retrieved April 13, 2004, from http://www.sfu.ca/media-lab

Leland, J., Gordon, D., Underwood, A., Weingarten, T., \& Figuero, A. (1999). The secret life of teens. Newsweek, 133(19), 44-50.

Montgomery, K. (2000). Youth and digital media: A policy research agenda. Journal of Adolescent Health, 27, 6168.

Nachmias, R., Mioduser, D., \& Shemla, A. (2003). Information and communication technologies usage by students in an Israeli high school. Retrieved April 13, 2004, from http://muse.tau.ac.il/ publications/ICT.pdf

Patton, M. Q. (2002). Qualitative research and evaluation methods. (3 ${ }^{\text {rd }}$ ed.). California: Sage.

Prezza, M., Pacilli, M. G., \& Dinelli, S. (2004). Loneliness and new technologies in a group of Roman adolescents. Computers in Human Behavior, 20, 691-702.

Rideout, V. J., Foehr, U. G., Roberts, D. F., \& Brodie, M. F. (1999). Kids and media @ the new millennium. A comprehensive national analysis of children's media use. A Kaiser Family Foundation Report. Retrieved May 10, 2004, from http://www.kff.org/content/1999/1535

Roberts, D. F. (2000). Media and youth: Access, exposure, and privatization. Journal of Adolescent Health, $27,8-14$.

The IPJP is a joint project of Rhodes University in South Africa and Edith Cowan University in Australia. This document is subject to copyright and may not be reproduced in whole or in part via any medium (print, electronic or otherwise) without the express permission of the publishers. 
Savahl, S., \& September, R. (2004). Information technology and children's communication patterns. Unpublished report, University of the Western Cape, Bellville.

September, R., \& Savahl, S. (2002). The influence of new information and communication technologies on children's lives. The South African study. Unpublished report, Child and Youth Research and Training Programme, University of the Western Cape, Bellville.

Shaw, T. (2002). Chat rooms and adolescent communication: Where do schools fit in? Multimedia Schools, 9, 35-42.

Skinner, H., Biscope, S., Poland, B., \& Goldberg, E. (2003). How adolescents use technology for health information: Implications for health professionals from focus group studies. Journal of Medical Internet Research, 5, 32-46.

Stahl, C., \& Fritz, N. (2002). Internet safety: Adolescents' self report. Journal of Adolescent Health, 31, 7-10.

Strasburger, V. C. (2004). Children, adolescents, and the media. Current Problems in Pediatric and Adolescent Health Care, 34, 54-113.

Suler, J. (1998). Adolescents in cyberspace: The good, the bad and the ugly. Retrieved June 14, 2004, from http://www.rider.edu/suler/psycber/adols.html

Suoranta, J. (2003). Youth and information and communication technologies. Retrieved May 10, 2004, from http://www.un.org/esa/socdev/unyin/helsinki/ch12-ict.suoranta.doc

Walsh, D. A. (2000). The challenge of the evolving media environment. Journal of Adolescent Health, 2, 69-72.

Walton, M., \& Jansen, C. (2003). Drawing the line: Violence and other issues in children's use of video games and gaming. Unpublished paper, HSRC seminar, Cape Town.

Wolak, J., Mitchell, K. J., \& Finkelhor, D. (2003). Escaping or connecting? Characteristics of youth who form close online relationships. Journal of Adolescence, 26, 105-119.

Wright, C. (2001). Children and technology: Issues, challenges, and opportunities. Childhood Education, $78,37-49$.

Ybarra, M. L., \& Mitchell, K. J. (2004). Youth engaging in online harassment: Associations with caregiver-child relationships, Internet use and personal characteristics. Journal of Adolescence, 27, 319-336.

The IPJP is a joint project of Rhodes University in South Africa and Edith Cowan University in Australia. This document is subject to copyright and may not be reproduced in whole or in part via any medium (print, electronic or otherwise) without the express permission of the publishers. 